\title{
In Situ Wire Drawing of Phosphate Glass in Polymer Matrices for Material Extrusion 3D Printing
}

\author{
J. Gilberto Siqueiros ${ }^{1,2}$ and David A. Roberson ${ }^{1,2}$ \\ ${ }^{1}$ Polymer Extrusion Lab, W.M. Keck Center for 3D Innovation, The University of Texas at El Paso, El Paso, TX 79968, USA \\ ${ }^{2}$ Department of Metallurgical, Materials and Biomedical Engineering, The University of Texas at El Paso, El Paso, TX 79968, USA \\ Correspondence should be addressed to David A. Roberson; droberson@utep.edu
}

Received 9 March 2017; Revised 22 May 2017; Accepted 28 May 2017; Published 5 July 2017

Academic Editor: J. M. Kenny

Copyright (c) 2017 J. Gilberto Siqueiros and David A. Roberson. This is an open access article distributed under the Creative Commons Attribution License, which permits unrestricted use, distribution, and reproduction in any medium, provided the original work is properly cited.

\begin{abstract}
A strategy to increase the amount of materials available for additive manufacturing platforms such as material extrusion $3 \mathrm{D}$ printing (ME3DP) is the creation of printable thermoplastic composites. Potential limiters to the incorporation of filler materials into a thermoplastic resin include agglomeration of the filler materials, which can compromise the mechanical properties of the material system and a static morphology of the filler material. A potential solution to these issues is the use of filler materials with low glass transition temperatures allowing for a change in morphology during the extrusion process. Here, we successfully demonstrate the drawing of phosphate glass particles into a wire-like morphology within two polymeric systems: (1) a rubberized acrylonitrile butadiene styrene (ABS) blend and (2) polylactic acid (PLA). After applying a normalization process to account for the effect of air gap within the 3D printed test specimens, an enhancement in the mechanical properties was demonstrated where an increase in strength was as high as $21 \%$ over baseline specimens. Scanning electron microanalysis was used to characterize the fracture surface and wire drawing efficacy. Factors affecting the ability to achieve wire drawing such as polymer viscosity and print temperature are also highlighted.
\end{abstract}

\section{Introduction}

A key enabler for the advancement of additive manufacturing (AM) is the creation of new material systems with a wider range of physical properties while maintaining compatibility with $3 \mathrm{D}$ printing capital equipment platforms. If we take, for example, material extrusion 3D printing (ME3DP), which is based on the trademarked fused deposition modeling $\left(\mathrm{FDM}^{\mathrm{TM}}\right)$ technology, there are limitations to the physical attributes of fabricated parts due to the dependence of this AM platform on thermoplastics such as acrylonitrile butadiene styrene (ABS), polylactic acid (PLA), and polycarbonate (PC). As is the case with most thermoplastics, ABS, PLA, and PC have a high molecular weight and their polymer chains weaken rapidly at temperatures approaching their glass transition temperature $\left(T_{q}\right)$ yielding a viscous phase that can be extruded and solidified upon cooling, a characteristic which is the key enabler for FDM-type AM [1]. Brittleness is one detrimental quality that is present in most thermoplastics and can be reduced with the addition of elastomers and plasticizers $[2,3]$. Reducing brittleness and improving elastic properties in thermoplastics for ME3DP technologies have been previously studied by Siqueiros et al. [4] where the addition of the elastomer, styrene ethylene butylene styrene grafted with maleic anhydride (SEBS-g-MA) at different loadings (by wt\%) was blended into ABS in order to modify its elastic properties while still maintaining compatibility with conventional FDM-type printing platforms. While polymer blending is one strategy for expanding the materials pallet for the ME3DP platform, there is still a limitation to the amount of achievable property augmentation due to the chemical composition and physical similitudes of various miscible polymers. The addition of metals, clays, carbon fibers, and other fillers to polymeric materials has been extensively researched in both academia and industry to enhance more drastically a given desired physical quality in order to satisfy a given application [5-8]. Improving mechanical properties, modifying thermal conductivity, and 
increasing elasticity are just a few examples of how polymer physical properties can be altered by the addition of fillers. In the area of ME3DP, this technique has also been applied where many examples can be found in literature [9-21]. In these works, polymers have been doped with metals, carbon fibers, carbon pastes, natural fibers, clays, and other materials in order to alter physical properties such as thermal and electrical conductivity, rheology, stiffness, strength, and elasticity, among other material properties. For example, Hwang et al. [19] explored the effect of the addition of metallic fillers on part warping and thermal conductivity of ABS, Shemelya et al. [21] demonstrated the creation of a tunable radiation shielding material based on a PC matrix loaded with tungsten at different loading percentages, and specific to the application of 3D printing, and Torrado et al. [22] explored the effect of additives on the mechanical property anisotropy based on part build orientation. The addition of fillers into polymers known to be compatible with ME3DP platforms gives the opportunity to expand the application of this manufacturing process without changes to capital equipment as discussed by Roberson et al. [20].

In some cases, the addition of additives has detrimental effects on the mechanical properties of the composite. A wellknown problem in the addition of nonpolymeric fillers in to ME3DP polymer materials is agglomeration. As mentioned above, Torrado et al. [22] studied the effects of additives on $\mathrm{ABS}$ for ME3DP and one of the conclusions drawn from this work was that particle agglomeration affected the overall mechanical properties of ABS, especially the ultimate tensile strength (UTS), where a reduction from $33.96 \mathrm{MPa}$ to $20.70 \mathrm{MPa}$ was observed due to the addition of $2.5 \%$ by weight of Zinc Oxide ( $\mathrm{ZnO})$ nanorods. Scanning electron microanalysis revealed that the nanorods had agglomerated. It is worth noting that this previous work did not involve the use of a functionalization process to modify the $\mathrm{ZnO}$ prior to melt compounding. From literature it is known that nonhomogeneous dispersion, agglomeration of particles, and poor attachment of additives to the polymer matrix are the main problems behind these negative effects on mechanical properties [5, 18, 22, 23]. A key aspect of loading polymeric materials with compositing agents such as carbon fibers is that the morphology of the filler material within the polymer matrix is largely predetermined.

The work presented here explores the possibility of loading a polymer matrix with a filler material whose morphology could be altered during the $3 \mathrm{D}$ printing process. The filler selected for this study is a phosphate glass (P-glass) which was combined with two polymer systems known for their ME3DP compatibility: (1) PLA, which is commonly used particularly in home-use or desktop grade ME3DP platforms; and (2) a version of the ABS:SEBS-g-MA blend first reported by Siqueiros et al. [4] (ABS blended with SEBS-g-MA in a $50: 50$ by weight ratio). P-glass was chosen as a filler because this material has similar thermal processing parameters to many thermoplastic polymers, meaning that the chance of initiating wire drawing within our matrix materials was likely [24]. The similar processing temperatures enabled an attempt to achieve in situ wire drawing of the P-glass particles within the polymer matrix with the end goal of mitigating

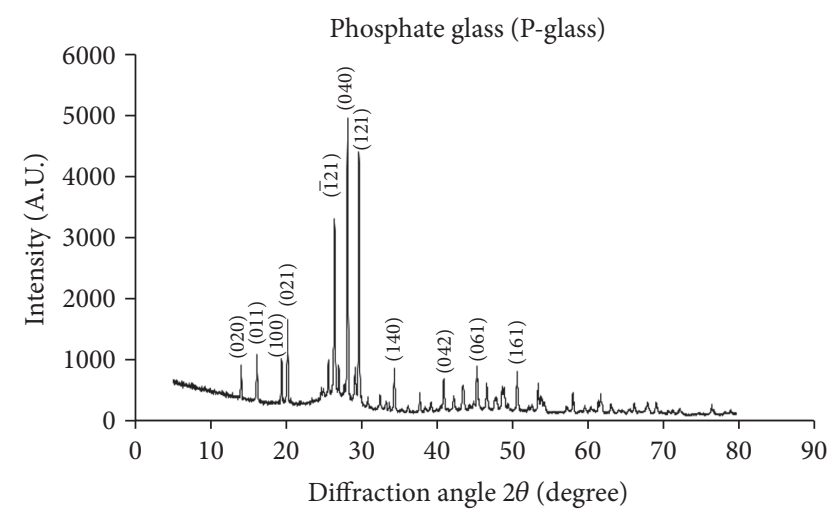

FIGURE 1: XRD spectra of the P-glass material used in this study.

particle agglomeration and improving the particle/matrix adhesion by wiring down agglomerated particles of P-glass within the polymer matrix allowing them to act as fiber reinforcement. Besides reducing particle agglomeration and improving mechanical properties, P-glass particles could enhance the insulating properties of these two polymers. Glasses are known for their good thermal insulating properties $[25,26]$, that is why, in an effort to expand the applications of ME3DP, this composite material could later be used as thermal insulator for a multimaterial ME3DP functional component necessitating thermal management such as $3 \mathrm{D}$ printed structural electronics $[27,28]$.

\section{Experimental Procedure}

Phosphate glass was created following a method by Gupta et al. where a mixture composed of a molar composition of $50 \%$ tin fluoride $\left(\mathrm{SnF}_{2}\right), 20 \%$ tin oxide $(\mathrm{SnO})$, and $30 \%$ phosphorous pentoxide $\left(\mathrm{P}_{2} \mathrm{O}_{5}\right)$ [24]. The ingredients were tumble mixed until the desired homogeneity was achieved and then placed into a glassy carbon crucible. The crucible was then placed into an oven (Lindberg/Blue M, Thermo Electron Corporation, Germany) at a temperature of $450^{\circ} \mathrm{C}$ for 70 minutes. The mixture in its liquid stage was then quenched in a stainless steel pan at room temperature. After quenching, the glass was annealed at $130^{\circ} \mathrm{C}$ for 90 minutes in a VWR horizontal forced air safety oven (Radnor, PA, USA). The resulting phosphate glass was then processed in a ball mill for 5 minutes. After ball milling the powder was chemically analyzed by X-ray diffraction (XRD) using a Bruker D8 Quest diffractometer (Bruker Corporation, Germany) operating with $\mathrm{Cu} \mathrm{K}-\alpha$ radiation (1.54 $\AA$ ). The resulting spectra (Figure 1) were a $100 \%$ match to tin fluorotrioxophosphate (phosphate glass). Figure 2(a) is a SEM micrograph of the ball milled phosphate glass particles. Measurement of the particles from the SEM image revealed a highly variable particle size distribution (coefficient of variation $=1.19$ ) with an average size of $9.68 \mu \mathrm{m}$ (Figure 2(b)).

In order to study the behavior of phosphate glass as an additive in polymers known for their ME3DP capabilities, PLA and the ABS-based blend discussed above were used as matrix materials. The polymers used in this study were 


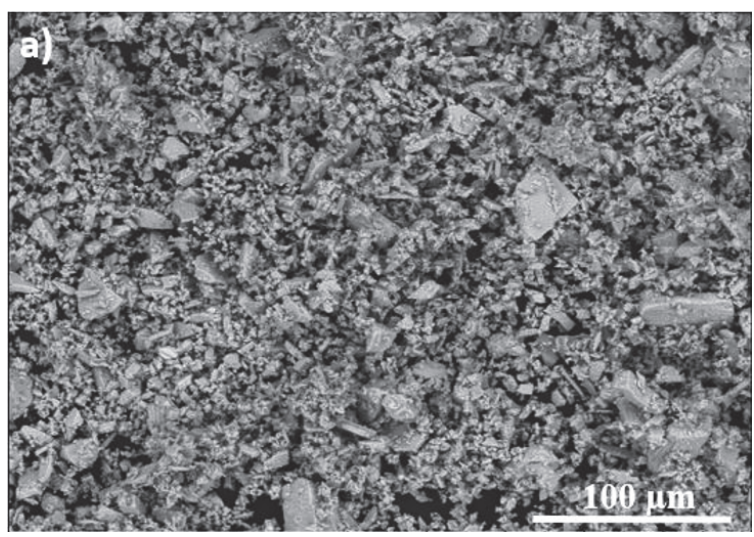

(a)

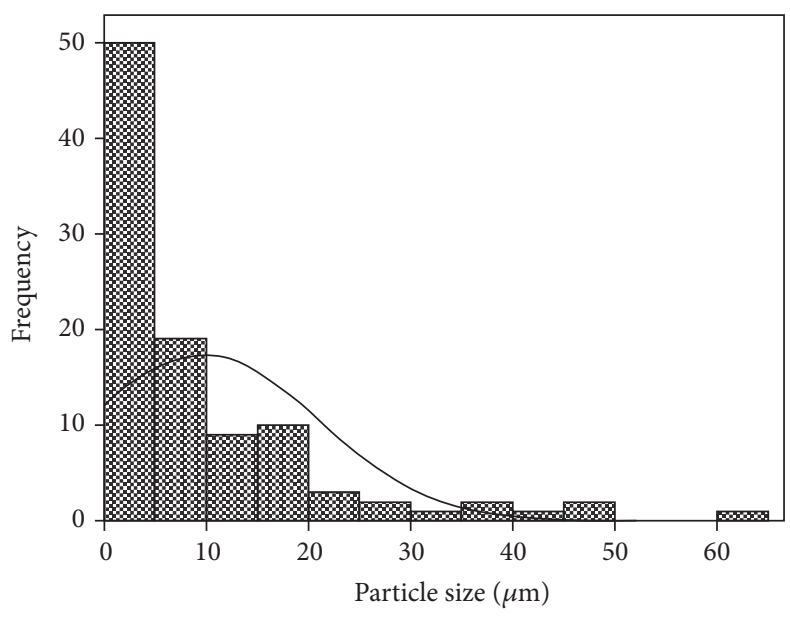

(b)

FIgURE 2: (a) SEM micrograph of P-glass particles and (b) size distribution of particles.

(1) PLA (grade 4043D NatureWorks, Blair, NE, USA) and (2) a polymer blend composed of a 50:50 weight ratio of ABS (grade MG94, SABIC, Pittsfield, MA) and SEBS-g-MA (Grade FG1901 Kraton, Houston, TX, USA). The elastomeric blend was previously studied by our group for the use in FDM-type processes and was demonstrated as a $3 \mathrm{D}$ printable material [4]. All polymers were received in pellet form the respective suppliers. In this study, the ABS:SEBS-g-MA blend was compounded first using a Dr Collin ZK 25 T twin screw extruder compounder (Collin Lab and Pilot Solutions, Inc., Norcross, GA, USA) following parameters documented in Siqueiros et al. [4] and then mechanically pelletized prior to melt compounding with the P-glass particles.

Before melt compounding, the filler material was subjected to a functionalization process intended to facilitate particle/matrix adhesion as well as facilitate improved dispersion of the filler material within the polymer matrix. The functionalization process consisted of a silane treatment on the additive before compounding; it must be mentioned that two different silanes were used in this experiment, one geared for the PLA matrix (3-Glycidyloxypropyl)trimethoxysilane and the other one towards the ABS:SEBS-g-MA blend Vinyltrimethoxysilane both purchased from Aldrich Chemistry (St. Louis, MO, USA). Our group has used a similar functionalization process in prior work where polycarbonate was the matrix material [21]. Before extrusion, the polymer pellets were dried using a compressed air dryer (Dri-Air CFAM Micro-Dryer, East Windsor, Connecticut, USA). PLA was dried at a temperature of $80^{\circ} \mathrm{C}$ for 4 hours and the ABS:SEBS-g-MA blend was dried at $70^{\circ} \mathrm{C}$ for a 2 -hour period. The limited quantity of phosphate glass necessitated the use of a small batch extruder; therefore, the melt compounding process was performed with the use of a desktop grade Filabot EX2 extruder (Filabot, Barre, VT, USA) in order to accommodate composite batches of $100 \mathrm{~g}$. The extruder was used in conjunction with the belt puller from the Collin $\mathrm{ZK}$ $25 \mathrm{~T}$ extruder to maintain a constant diameter of $1.75 \mathrm{~mm}$, a standard diameter used on many FDM-type platforms. The
TABLE 1: Extrusion temperatures.

\begin{tabular}{lc}
\hline Material system & Extrusion temperature ${ }^{\circ} \mathrm{C}$ \\
\hline ABS:SEBS-g-MA & 210 \\
ABS:SEBS-g-MA, P-glass 5\% & 230 \\
ABS:SEBS-g-MA, P-glass 10\% & 235 \\
ABS:SEBS-g-MA, P-glass 20\% & 240 \\
PLA & 190 \\
PLA, 2.5\% P-glass & 205 \\
PLA, 5\% P-glass & 215 \\
PLA, 10\% P-glass & 220 \\
PLA, 15\% P-glass & 235 \\
\hline
\end{tabular}

extrusion temperatures for the composite systems evaluated in this study are seen in Table 1.

In order to characterize the mechanical properties of the different polymer composite systems, test specimens were printed using a Lulzbot TAZ 4 (Aelph Objects Inc., Loveland, Colorado, USA) outfitted with a $0.8 \mathrm{~mm}$ nozzle tip. The printer was modified to accept $1.75 \mathrm{~mm}$ diameter filament through the installation of an E3D V6 hotend (E3D-Online Limited, Chalgrove, Oxford shire, UK). The test specimens were printed with $100 \%$ infill in a rectilinear pattern consisting in alternating layers of 0 and 90 degrees. The dimensions of the specimens followed ASTM standard D638-14 [29] Type V. Figure 3 represents the printed tensile test specimens for one of the systems. The printing parameters for all the systems are shown in Table 2.

Tensile testing was carried out using an Instron 5866 (Instron, Norwood, Massachusetts, USA) loaded with a $10 \mathrm{kN}$ load cell following ASTM standard D638-14 [29]. All tests were performed at a strain rate of $10 \mathrm{~mm} / \mathrm{min}$ at room temperature on sample pools of 3 to 6 specimens per material system and the UTS and percent elongation at break (\% EL) were recorded for each specimen. 


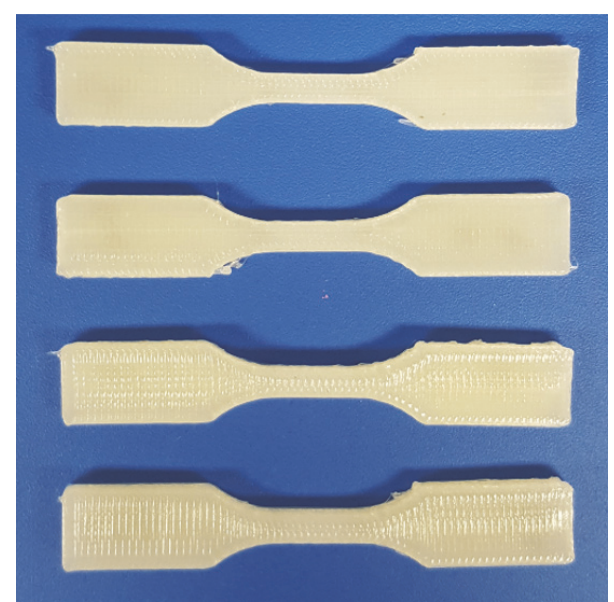

FIgURE 3: Printed tensile specimens (PLA, phosphate glass 10\%).

TABLe 2: Printing parameters.

\begin{tabular}{lcc}
\hline Material system & $\begin{array}{c}\text { Nozzle } \\
\text { temperature } \\
{ }^{\circ} \mathrm{C}\end{array}$ & $\begin{array}{c}\text { Bed } \\
\text { temperature } \\
{ }^{\circ} \mathrm{C}\end{array}$ \\
\hline ABS:SEBS-g-MA baseline & 240 & 110 \\
ABS:SEBS-g-MA, P-glass 5\% & 240 & 110 \\
ABS:SEBS-g-MA, P-glass 10\% & 240 & 110 \\
ABS:SEBS-g-MA, P-glass 20\% & 240 & 110 \\
PLA baseline & 220 & 110 \\
PLA, P-glass 2.5\% & 220 & 110 \\
PLA, P-glass 5\% & 220 & 110 \\
PLA, P-glass 10\% & 240 & 110 \\
PLA, P-glass 15\% & 240 & 110 \\
\hline
\end{tabular}

Fracture surface analysis of spent tensile test specimens was carried out through the use of a Hitachi TM-1000 scanning electron microscope (SEM; Hitachi High-Technologies Europe $\mathrm{GmbH}$, Germany) operating at a $15 \mathrm{kV}$ accelerating potential and equipped with a backscatter electron detector. Due to the nonconductive nature of polymeric surfaces, the specimens were gold coated using a JEOL Smart Coater (JEOL USA, Inc, Peabody, MA) to reduce electron charging. Two to three different test specimens from each system were analyzed in order to characterize the in situ wire drawing of phosphate glass particles as well as the failure modes and fracture surface morphology within each material system.

Melt flow rate analysis was performed by following ASTM standard D1238-13 [30] (procedure A) using a Tinius Olsen (Horsham, PA, USA) MP1200 melt flow indexer (MFI). Prior to performing the test, filament specimens from the different material systems were pelletized to allow introduction into the melt flow indexer in $7 \mathrm{~g}$ sample sizes. For comparison purposes, all the ABS SEBS-g-MA blend systems were tested at a temperature of $230^{\circ} \mathrm{C}$ with a $3.8 \mathrm{~kg}$ test load. The PLA systems were tested at a temperature of $210^{\circ} \mathrm{C}$ with a $2.16 \mathrm{~kg}$ test load. The melt flow rates of all the systems were collected and will be discussed in greater detail below.

\section{Results}

3.1. Fractography. Fracture surface analysis confirmed the in situ wire drawing of phosphate glass particles within the ABS:SEBS-g-MA polymer matrix as is seen in Figure 4(a). Phosphate glass particles were elongated into a rod shape form with diameters ranging from 0.5 to $2 \mu \mathrm{m}$. The presence of drawn wires supports the theory and motivation behind this study: because of the similar processing temperatures between polymers and P-glass at the moment of deposition during the $3 \mathrm{D}$ printing process, particles of P-glass would experience enough shear forces that would make them elongate within the polymer matrix. In contrast, PLA loaded with 5\% P-glass did not show signs of wire drawing as can be observed in Figure 4(b). Examination of the PLA specimens loaded with P-glass under SEM revealed that the P-glass particles did not show signs of elongation (Figure 5). This could be due to the low viscosity of PLA during filament extruding and ME3DP. Viscosity plays an important role in the elongation of the P-glass particles; in this study the ABS:SEBS-g-MA blend which has a higher $T_{g}$ of around $120^{\circ} \mathrm{C}$ compared to the $T_{g}$ of PLA of $70^{\circ} \mathrm{C}$ (as determined by the max $\tan \delta$ of dynamic mechanical analysis scans) possesses a greater viscosity at the moment of deposition resulting in higher shear forces within the composite filament allowing in situ wire drawing of P-glass particles within the polymer matrix. Figure 6 is a schematic representation of the in situ wire drawing process of P-glass in the ABS:SEBSg-MA matrix during deposition. PLA is usually $3 \mathrm{D}$ printed at temperatures ranging from $170^{\circ} \mathrm{C}$ to $220^{\circ} \mathrm{C}$, and for this experiment it was necessary that the print temperatures be above $220^{\circ} \mathrm{C}$ to avoid clogging of the print nozzle by the Pglass, which, at the same time, reduced the viscosity of PLA negating any shear forces which would elongate the P-glass particles.

When the loading of P-glass was increased to $10 \%$ by weight and above, agglomeration played a key role in reducing the mechanical properties, specifically the property of UTS. In the case of ABS:SEBS-g-MA loaded at $10 \%$ and $20 \%$ P-glass, the SEM micrographs of the fracture surfaces revealed that there were more particles that did not elongate during deposition as indicated by white circles on Figure 7. The particle size of the undrawn P-glass particles ranged from $15 \mu \mathrm{m}$ to $2.5 \mu \mathrm{m}$. The agglomeration between P-glass particles in the 20\% P-glass ABS:SEBS-g-MA system (specified on Figure 7 (b) by a rectangle) interfered with the proper in situ wire drawing of the P-glass and acted as a crack propagation site.

In order to investigate the effect of print temperature on the efficacy of the in situ wire drawing of P-glass particles in the ABS:SEBS-g-MA 10\% P-glass system, two specific print temperatures were experimented with, $240^{\circ} \mathrm{C}$ and $280^{\circ} \mathrm{C}$. Based on SEM images, there was not a clear difference between the two print temperatures in terms of the amount of P-glass particles that were in situ wire drawn as can be seen on the high magnification inset images representing the printing temperatures of $240^{\circ} \mathrm{C}$ and $280^{\circ} \mathrm{C}$ (Figure 8). The only clear difference between the print temperatures was observable when comparing the lower magnification SEM images where 


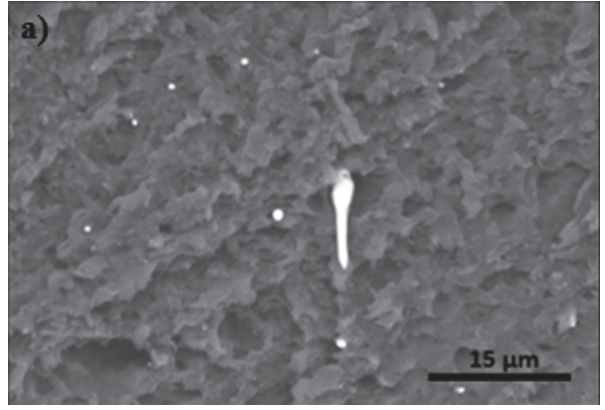

(a)

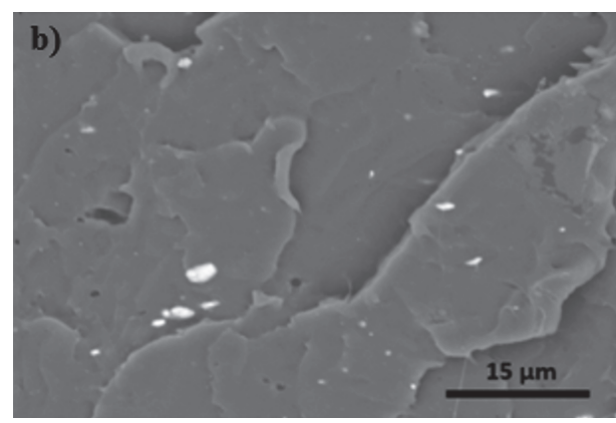

(b)

FIgUre 4: Fracture surface of 5\% P-glass loaded into (a) ABS:SEBS-g-MA and (b) PLA.

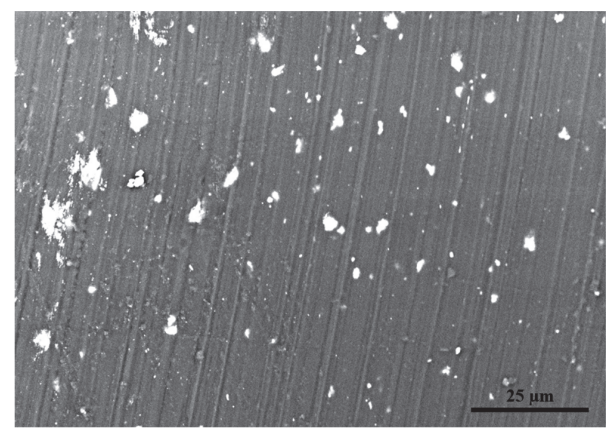

FIGURE 5: Scanning electron micrograph of a filament specimen of PLA loaded with P-glass at a loading of $15 \%$ by weight.

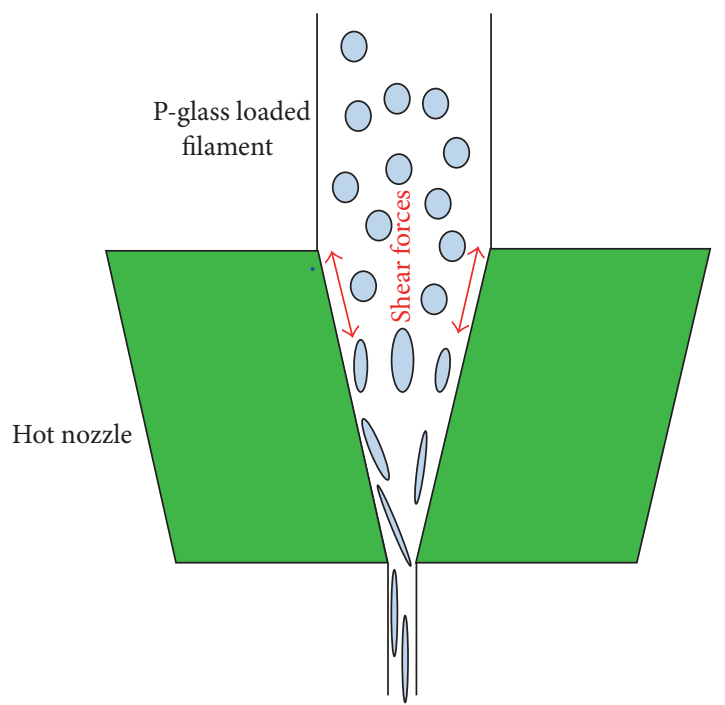

FIGURE 6: Schematic depicting the in situ wire drawing of P-glass during the $3 \mathrm{D}$ printing process.

an overall more ductile fracture occurred, as indicated by a greater amount of plastic deformation on the fracture surface of the specimen printed at $280^{\circ} \mathrm{C}$ (Figure $8(\mathrm{~b})$ ).

In the case of the PLA/P-glass system there was no observable evidence of in situ wire drawing of P-glass particles based on fractographic analysis. The SEM images in Figures 9(a) and 9(b) are representative images of PLA loaded at the $2.5 \%$ and $10 \%$ by weight P-glass. In these images and throughout the fracture surface there were no signs of wire drawn P-glass particles. A noteworthy observation while analyzing the fracture surface of this system was the robust attachment of the phosphate glass particles to the PLA matrix, a plausible reason behind the increase of UTS for the $2.5 \%$ and 5\% loading as well as the incremental increase in strain on every P-glass loading in PLA.

Agglomeration also played a factor in the reduction of the UTS in the higher P-glass loadings in the case of the PLA systems. Figure 10 is a SEM micrograph of the fracture surface of PLA loaded with $10 \%$ P-glass and the agglomerate size of phosphate glass in unit sizes ranging from 5 to $100 \mu \mathrm{m}$.

3.2. Tensile Test Results. The results of the tensile testing for the ABS:SEBS-g-MA loaded with P-glass systems are tabulated in Table 3 and graphically represented in Figures 11 and 12 . The best performer out of the three systems was the 5\% (by wt.) P-glass loading, which had a UTS value of $14.8 \pm 0.2 \mathrm{MPa}$ as compared to the baseline value of $14.4 \pm$ $0.2 \mathrm{MPa}$. Though the UTS was not significantly increased, the lack of a negative result to the mechanical properties for the 5\% P-glass loading confirms the theory behind this study that in situ wire drawing of an additive into a polymer matrix diminishes the detrimental effects of agglomeration and provides a more stable attachment to the polymer matrix. In the case of the material loaded at $10 \%$ by weight there was a minimal but not statistically significant reduction of UTS compared to the baseline. The fractographic evidence indicated some agglomeration and large P-glass particles could have been detrimental to the mechanical properties at this percent loading. The significant reduction of UTS for the material loaded with $20 \%$ by weight P-glass was most likely caused by voids within the material as observed on the fracture surface of the tensile specimens as well as particle agglomeration. Figure $13(\mathrm{a})$ is a SEM image of the $20 \%$ P-glass fracture surface where particle agglomeration and voids throughout the surface are observable. Further analysis of extruded filament corresponding to the $20 \%$ by weight loading also indicated particle agglomeration and voids as can be observed in Figure 13(b).

In terms of $\%$ EL at break, the best performer was also the $5 \% \mathrm{P}$-glass loading as the elongation at break increased 


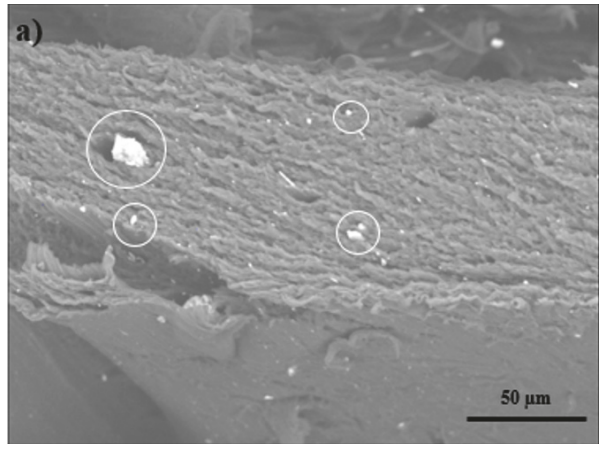

(a)

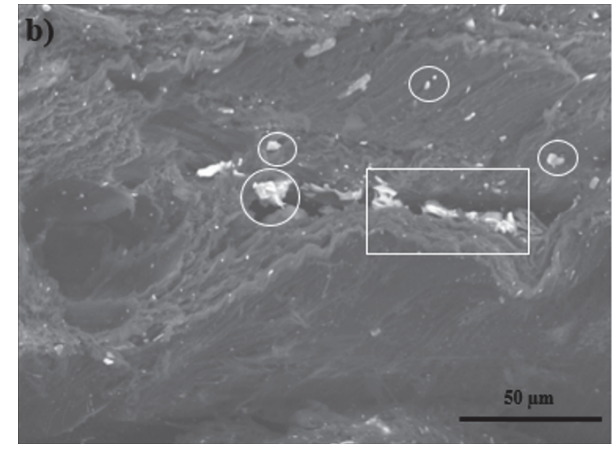

(b)

FIGURE 7: SEM micrographs of tensile test fracture surfaces of ABS:SEBS-g-MA loaded with (a) 10\% P-glass and (b) $20 \%$ P-glass.

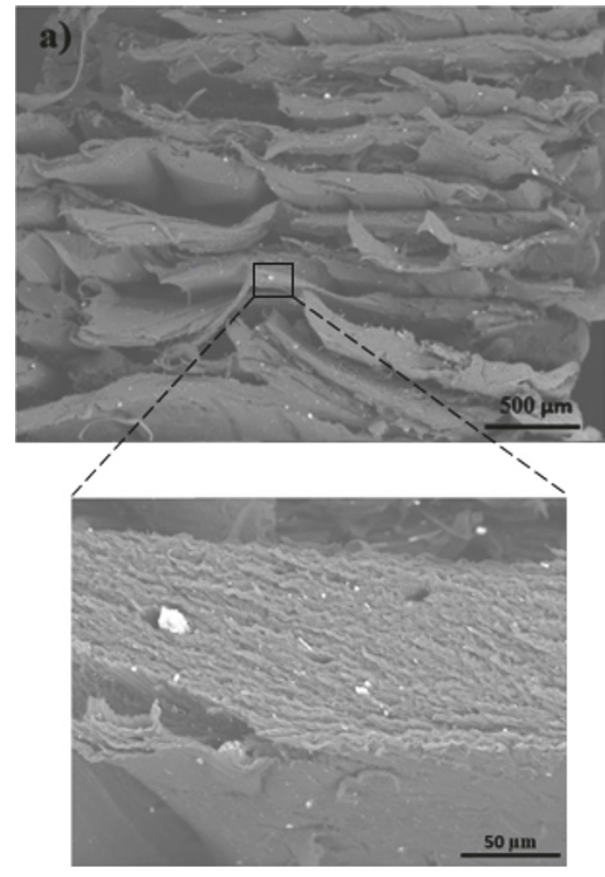

(a)

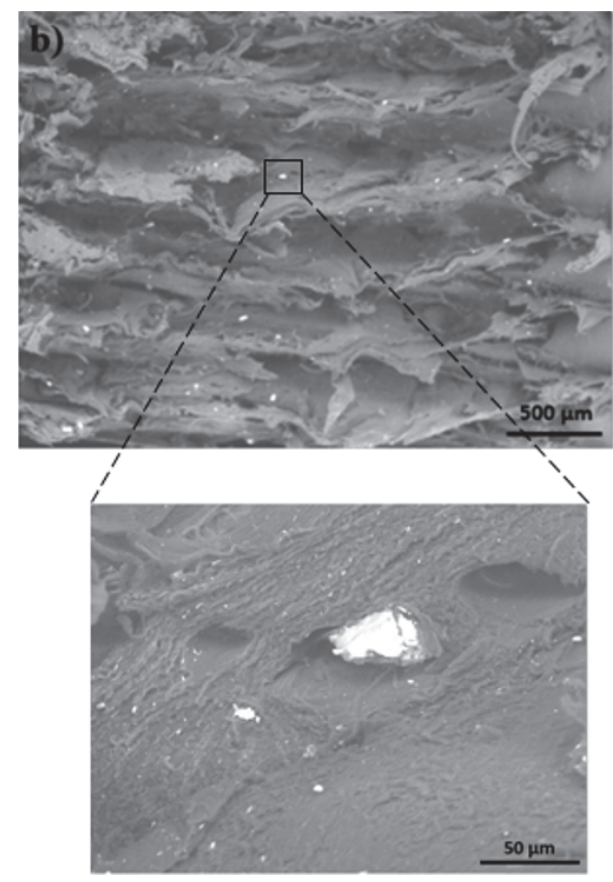

(b)

FIGURE 8: SEM micrographs of tensile specimens fabricated from ABS:SEBS-g-MA loaded with 10\% by weight P-glass and printed at (a) $240^{\circ} \mathrm{C}$ and (b) $280^{\circ} \mathrm{C}$.

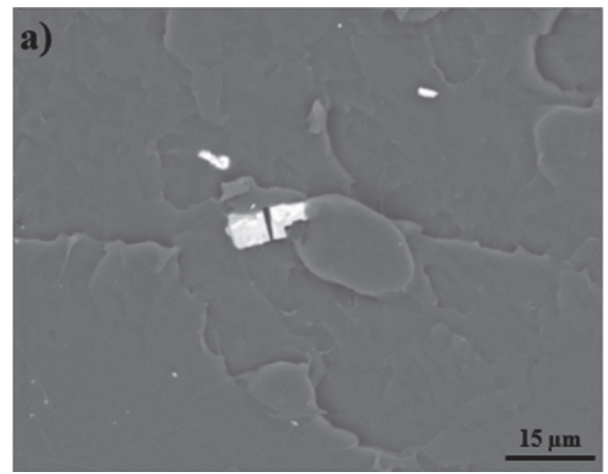

(a)

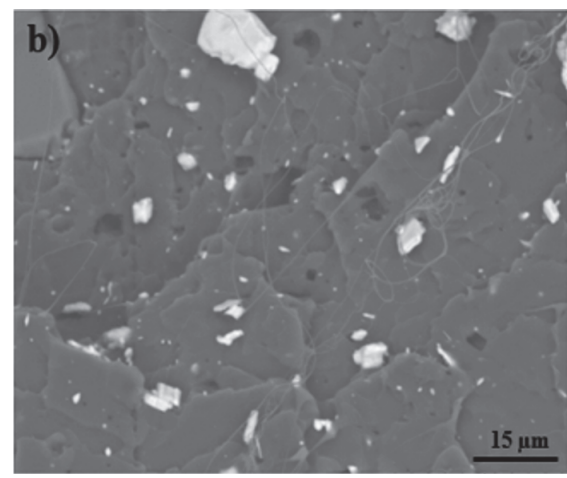

(b)

Figure 9: SEM micrographs of fracture surfaces of PLA loaded with P-glass at (a) $2.5 \%$ by weight and (b) $10 \%$ by weight. 
TABLE 3: Tensile rest results for ABS:SEBS-g-MA loaded with P-glass at various weight percentages.

\begin{tabular}{lccccc}
\hline Material & UTS (MPa) & ST. DEV & \% EL at break & ST. DEV & Sample size $(n)$ \\
\hline ABS:SEBS-g-MA, P-glass 5\% @240C & 14.8 & 0.2 & 69 & 4 & 4 \\
ABS:SEBS-g-MA, P-glass 10\% @240C & 14.1 & 1.3 & 49 & 63 & 14 \\
ABS:SEBS-g-MA, P-glass 20\% @240C & 11.0 & 0.5 & 54 & 14 & 5 \\
ABS:SEBS-g-MA, baseline @240C & 14.4 & 0.2 & 54 & 3 \\
\hline
\end{tabular}

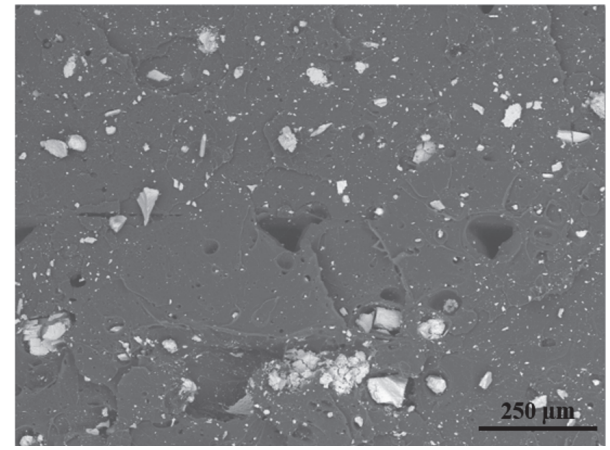

FIGURE 10: SEM micrograph of a fracture surface of PLA loaded with P-glass at $10 \%$ by weight.

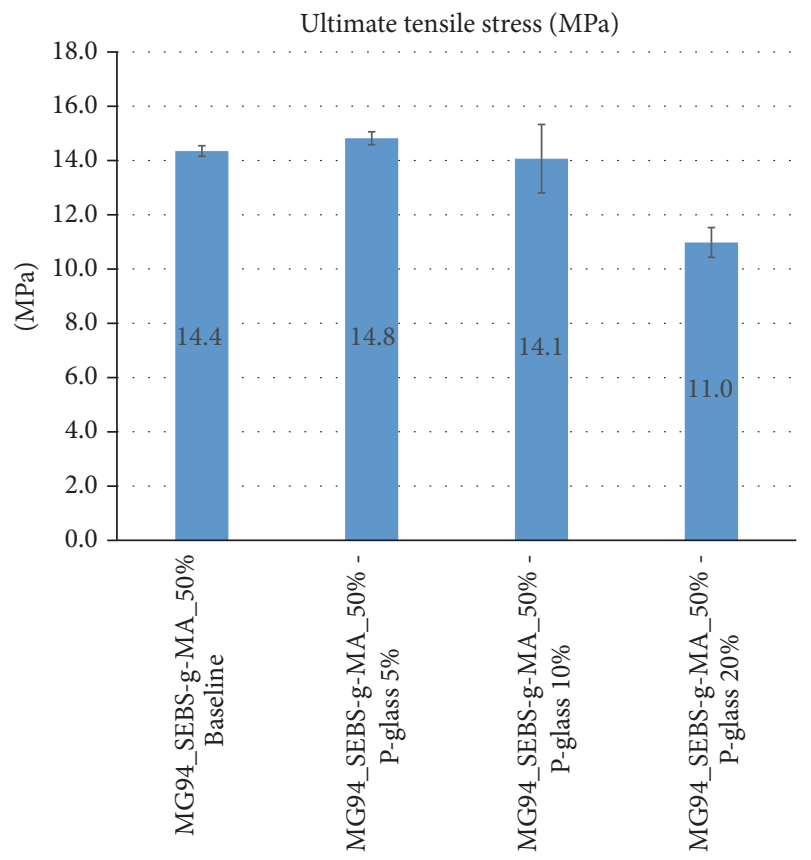

FIGURE 11: UTS values for the ABS:SEBS-g-MA/P-glass systems.

from $54 \pm 14 \%$ for the baseline specimens to $69 \% \pm 4 \%$. The only system which exhibited a reduction of \% EL at break as compared to baseline ABS:SEBS-g-MA specimens was the $10 \% \mathrm{P}$-glass loading printed at $240^{\circ} \mathrm{C}$. The reduction of percent elongation at break for this system occurred because of large P-glass agglomerates that acted as crack initiation sites as determined by the fractographic analysis in Figure 14 indicated by circles, where the longitude of middle right particle is around $34.5 \mu \mathrm{m}$ and bottom left 22.5 microns.

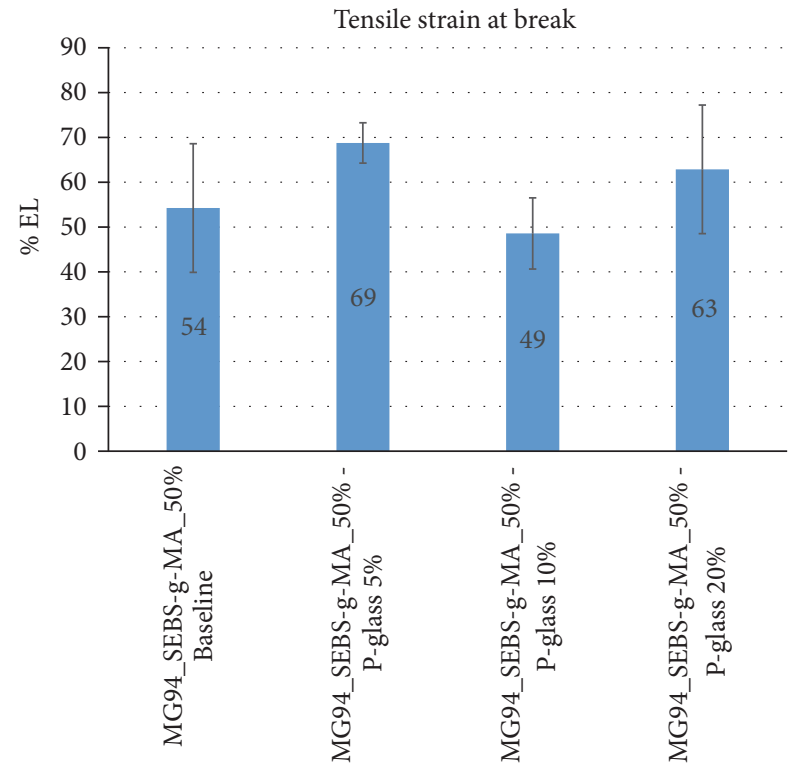

Figure 12: \% EL at break values for the ABS:SEBS-g-MA P-glass systems.

From SEM image analysis most elongated particles have a diameter ranging from 0.5 to $2 \mu \mathrm{m}$, whereas particles of the sizes shown in Figure 14 are too large to in situ wire draw within the polymer matrix and lead to detrimental effects on the mechanical properties of the printed part.

As mentioned before, in the case of the ABS:SEBS-gMA system loaded with $10 \%$ by weight P-glass, two different printing temperatures were studied in order to understand the effect of elevated process temperatures. Fractographic analysis on spent tensile specimens revealed that many $\mathrm{P}$ glass particles were not wire drawn within the polymeric matrix. Therefore, a second set of tensile test specimens was printed at a higher temperature $\left(280^{\circ} \mathrm{C}\right)$ to explore the relationship between temperature and the ability to draw $\mathrm{P}$ glass particles. There was not a clear difference in the amount of wire drawn particles compared to the previous printing temperature of $240^{\circ} \mathrm{C}$ based on fractographic evidence, but there was a difference in the mechanical properties as can be noted in Table 4 . There is a slight increase on the UTS in the system printed at $280^{\circ} \mathrm{C}$ and a noticeable increment in percent elongation at break (\% EL) compared to the ABS:SEBS-g-MA baseline specimens printed at the same temperature. This could be an indication that the P-glass particles printed at higher temperature parameters have a positive effect on the tensile behavior of the system, but the loss in viscosity does not allow in situ wire drawing of the 


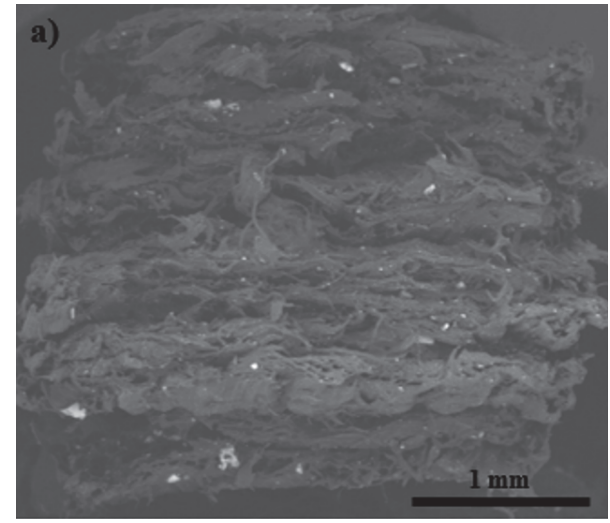

(a)

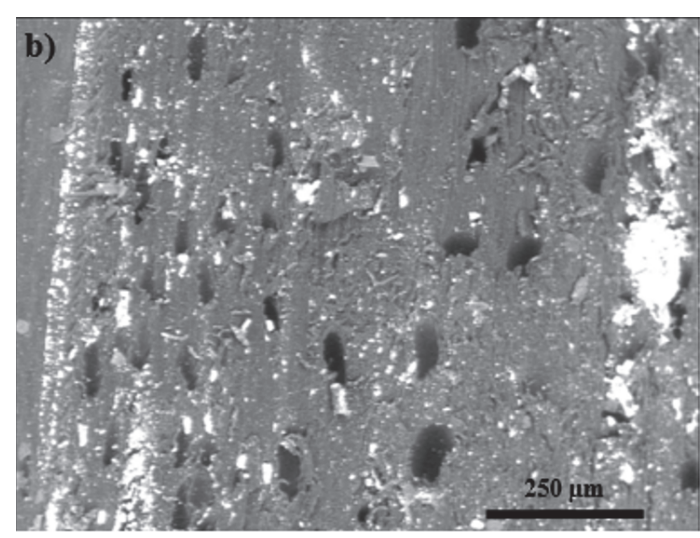

(b)

FIGURE 13: SEM micrographs of ABS:SEBS-g-MA loaded with P-glass at 20\% by weight, (a) fracture surface and (b) filament (tangential view).

TABLE 4: Tensile test results for ABS:SEBS-g-MA loaded with P-glass at 10\% by weight printed at different temperatures.

\begin{tabular}{|c|c|c|c|c|c|}
\hline Material & UTS (MPa) & ST. DEV & $\% \mathrm{EL}$ & ST. DEV & Sample size $(n)$ \\
\hline ABS:SEBS-g-MA, P-glass 10\%@240C & 14.1 & 1.3 & 48 & 8 & 3 \\
\hline ABS:SEBS-g-MA, P-glass 10\% @280C & 12.0 & 0.3 & 62 & 16 & 3 \\
\hline ABS:SEBS-g-MA@240C & 14.3 & 0.2 & 54 & 7 & 3 \\
\hline ABS:SEBS-g-MA@280C & 11.6 & 0.2 & 54 & 14 & 3 \\
\hline
\end{tabular}

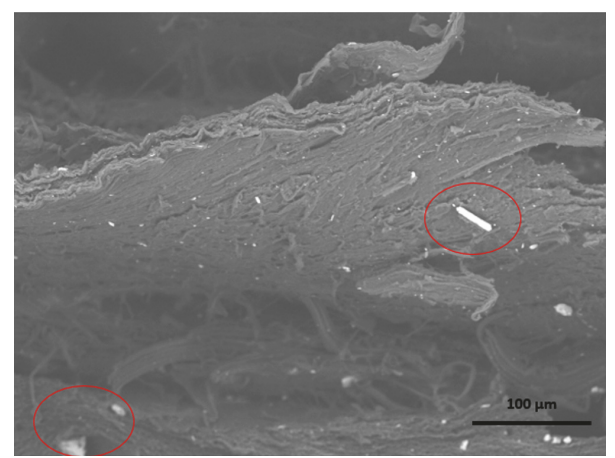

FIGURE 14: SEM micrograph of the fracture surface of a specimen of ABS:SEBS-g-MA loaded with P-glass at $10 \%$ by weight printed at $240^{\circ} \mathrm{C}$.

particles within the polymer matrix. Additionally, the higher temperature could have also led to an increase in fusion between print rasters as the increased heat would allow for a greater degree of subdiffusion to occur while the latent heat would increase the duration of any diffusion processes [31].

The tensile test results of the PLA loaded with P-glass are tabulated in Table 5 and graphically represented in Figures 15 and 16. While there was a slight increase of UTS values for the $2.5 \%$ and $5 \%$ by weight loading of P-glass compared to the pure PLA baseline, the increase was not statistically significant. Once the \% loading by weight increased to $10 \%$ and $15 \%$, the UTS decreased by $13 \%$ in the case of the $10 \%$ P-glass loading and a reduction of $24 \%$ for the $15 \%$ P-glass loading. The \% EL at break increased beyond error for the 2.5 and $15 \%$ by weight loadings of P-glass; the particles reduced the brittle nature of PLA indicated by an increase in the

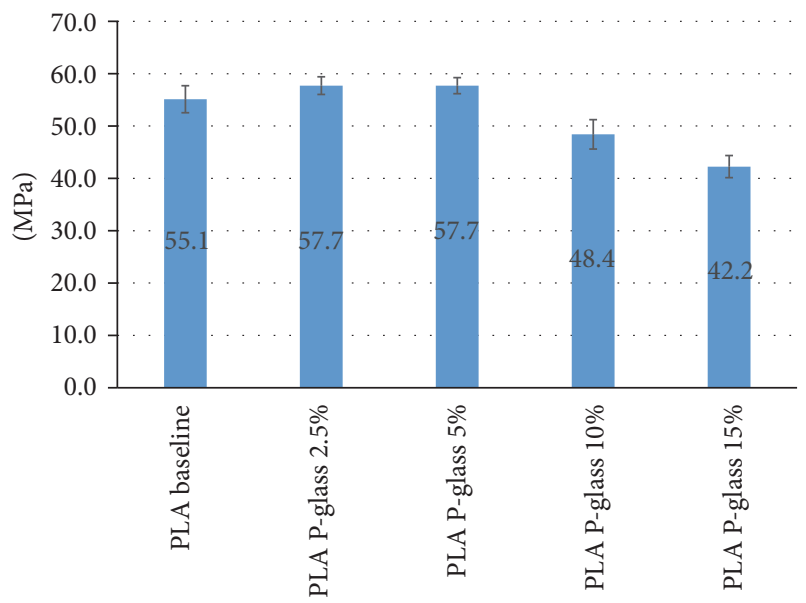

FIGURE 15: UTS values for PLA loaded with P-glass at various weight percentages.

elongation at break. However, there was no evidence of in situ wire drawn particles of P-glass in the PLA matrix.

As was the case for the ABS:SEBS-g-MA system loaded with $20 \%$ P-glass, the PLA P-glass $15 \%$ system exhibited the highest decrease in strength. The decrease in tensile strength was unexpected, so further investigation as to the cause of the observed malefic was warranted. The SEM micrographs of the PLA P-glass system also exhibited a high amount of voids present similar to the $20 \%$ P-glass ABS:SEBS-g-MA system. The presence of voids is a key factor in the reduction of UTS and there was a trend of voids increasing proportionally with the percent loading of P-glass. In order to normalize the UTS values with $100 \%$ filled tensile 
TABLE 5: Mechanical testing results for PLA loaded with P-glass at various weight percentages.

\begin{tabular}{lccccc}
\hline Material & UTS (MPa) & St. Dev & \% EL & St. Dev & Sample size $(n)$ \\
\hline PLA/P-glass 2.5\% & 57.7 & 1.7 & 6.0 & 2.2 & 5 \\
PLA/P-glass 5\% & 57.7 & 1.5 & 4.6 & 0.9 & 5 \\
PLA/P-glass 10\% & 48.4 & 2.8 & 4.4 & 0.9 & 5 \\
PLA/P-glass 15\% & 42.2 & 2.1 & 5.2 & 1.5 & 6 \\
PLA, baseline & 55.1 & 2.6 & 3.3 & 1.6 & 4 \\
\hline
\end{tabular}

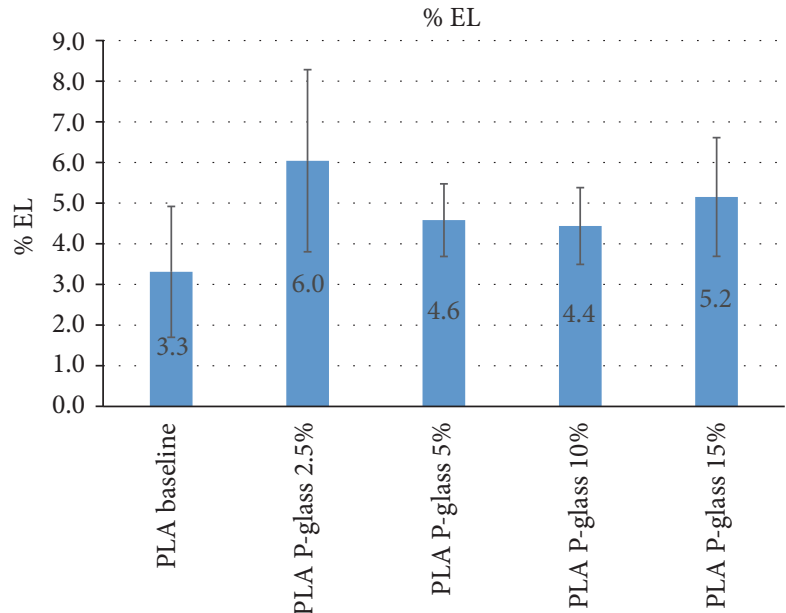

FIGURE 16: Percent elongation values for PLA loaded with P-glass at various weight percentages.

specimens for every system, density measurements following guidelines from ASTM Standard D792-13 [32] were made. The measurements were then compared to the theoretical density of each material system to create a normalization factor, which was then applied to the UTS results for each material system. Our group has utilized this strategy to assess the effect of additives on mechanical properties in previous work [21]. The specimens used for the density test were the grip section of the mechanical test specimens $(n=5$ for each sample pool). The test was performed with a Minerlab specific gravity kit (Minerlab LLC, Prescott, AZ, USA) and an analytical balance readable to $0.1 \mathrm{mg}$ Sartorius CP124S (H\&C Weighing Systems, Columbia, MD, USA). The results for the density test along with the normalized UTS and percent infill calculations are shown in Tables 6 and 7 for the ABS:SEBSg-MA and PLA systems, respectively. Figures 17 and 18 are graphical representations of these tables. The infill percent is the percentage of the measured density over theoretical density. It is notable that, after the normalization process, an appreciable increase in mechanical strength was revealed for both PLA and the ABS-SEBS-g-MA material systems over the baseline specimen pools.

In the case of the ABS:SEBS-g-MA system, there was an incremental increase in strength for all the loadings when compared to the baseline values. The previously noted trend of an increase in void content with an increase of Pglass loading was confirmed by the density measurements taken-meaning that the actual infill percentage decreases with the addition of P-glass. The maximum increase in UTS was no greater than $20 \%$ over the baseline values $(17.8 \mathrm{MPa}$ compared to $14.7 \mathrm{MPa}$ ) which is equal to the 10 and $20 \%$ by weight loading of P-glass. A similar trend was observed in the PLA system where the addition of P-glass led to an increase in strength with the exception of the 10\% load where the UTS remained equal to the baseline. Further experiments with the PLA/10\% by weight P-glass system were carried out as will be explained later.

3.3. Melt Flow Rate Analysis. Results of MFR measurements performed on the pelletized filament from all the systems are shown in Table 8. In the case of ABS:SEBS-g-MA, it was observed that increasing the loading percentage of the P-glass led to an incremental decrease in the MFR values ( $\mathrm{g} / 10 \mathrm{~min}$ ) which is indicative of an increase in viscosity. In contrast, increasing the loading percentage of P-glass within PLA led to a decrease in the viscosity as the percent loading of filler increased. A potential reason for this occurrence is the hygroscopic nature of PLA which increased with the content of P-glass. It must be noted that before the tests were made, no prior drying treatments were performed.

3.4. Further PLA/P-Glass System Analysis. After observing the high MFR results along with the lack of wire drawing within the PLA system, it was evident that the viscosity was not adequate to create enough shear forces to elongate the P-glass particles. One of the steps during our filament fabrication process involves a cooling method where the filament is run through a water bath. Due to hygroscopic nature of PLA, it was theorized that the filament absorbed moisture from the water bath. The NatureWorks technical data sheet indicates the MFR values for the 4043D grade of $6 \mathrm{~g} / 10 \mathrm{~min}$ using a $2.16 \mathrm{~kg}$ load and a temperature of $210^{\circ} \mathrm{C}$ [33]. The initial MFR results from the pelletized PLA filament resulted in values of $16.98 \mathrm{~g} / 10 \mathrm{~min}$ by using the same testing weight and temperature without performing any prior drying treatments. In an attempt to discombobulate the difference in results, a new MFR test was performed by drying the extruded PLA baseline filament for 4 hours at $80^{\circ} \mathrm{C}$ before the test in a VWR horizontal forced air safety oven (Radnor, PA, USA). New MFR measurements of the dried PLA extruded filament resulted in a value of $5.86 \mathrm{~g} / 10 \mathrm{~min}$, which is closer to the published value of $6 \mathrm{~g} / 10 \mathrm{~min}$. After interpreting the results of the dried PLA filament, a new set of test specimens of the PLA/P-glass $10 \%$ loaded system was printed. The reason behind choosing this loading percentage was that by selecting a higher loading 
TABLE 6: Normalized UTS data for the ABS:SEBS-g-MA system.

\begin{tabular}{|c|c|c|c|c|c|c|c|c|}
\hline Material & $\begin{array}{c}\text { Theoretical } \\
\text { density } \\
\left(\mathrm{g} / \mathrm{cm}^{3}\right)\end{array}$ & $\begin{array}{c}\text { Measured } \\
\text { density } \\
\left(\mathrm{g} / \mathrm{cm}^{3}\right) \\
\end{array}$ & ST DEV & $\%$ infill & $\begin{array}{l}\text { UTS }(\mathrm{MPa}) \\
\text { measured }\end{array}$ & ST DEV & $\begin{array}{l}\text { UTS (MPa) } \\
\text { normalized }\end{array}$ & ST DEV \\
\hline $\begin{array}{l}\text { ABS:SEBS-g-MA, } \\
\text { baseline }\end{array}$ & 0.98 & 0.96 & 0.0023 & $98 \%$ & 14.4 & 0.2 & 14.7 & 0.2 \\
\hline $\begin{array}{l}\text { ABS:SEBS-g-MA, } \\
\text { P-glass } 5 \%\end{array}$ & 1.11 & 0.98 & 0.0064 & $88 \%$ & 14.8 & 0.2 & 16.8 & 0.3 \\
\hline $\begin{array}{l}\text { ABS:SEBS-g-MA, } \\
\text { P-glass } 10 \%\end{array}$ & 1.25 & 0.99 & 0.0058 & $79 \%$ & 14.1 & 1.3 & 17.8 & 1.6 \\
\hline $\begin{array}{l}\text { ABS:SEBS-g-MA, } \\
\text { P-glass } 20 \%\end{array}$ & 1.51 & 0.94 & 0.0041 & $62 \%$ & 11 & 0.5 & 17.8 & 0.9 \\
\hline
\end{tabular}

TABLE 7: Normalized UTS data for the PLA system.

\begin{tabular}{|c|c|c|c|c|c|c|c|c|}
\hline Material & $\begin{array}{c}\text { Theoretical } \\
\text { density } \\
\left(\mathrm{g} / \mathrm{cm}^{3}\right)\end{array}$ & $\begin{array}{c}\text { Measured } \\
\text { density } \\
\left(\mathrm{g} / \mathrm{cm}^{3}\right)\end{array}$ & ST DEV & $\%$ infill & $\begin{array}{l}\text { UTS (MPa) } \\
\text { measured }\end{array}$ & ST DEV & $\begin{array}{l}\text { UTS (MPa) } \\
\text { normalized }\end{array}$ & ST DEV \\
\hline PLA baseline & 1.24 & 1.22 & 0.0017 & $98 \%$ & 55.1 & 2.6 & 56.0 & 2.6 \\
\hline PLA, P-glass $2.5 \%$ & 1.30 & 1.23 & 0.0031 & $95 \%$ & 57.7 & 1.7 & 61.0 & 1.8 \\
\hline PLA, P-glass 5\% & 1.36 & 1.26 & 0.0027 & $93 \%$ & 57.7 & 1.5 & 62.1 & 1.7 \\
\hline PLA, P-glass 10\% & 1.48 & 1.28 & 0.0059 & $86 \%$ & 48.4 & 2.8 & 56.0 & 3.3 \\
\hline PLA, P-glass 15\% & 1.60 & 1.11 & 0.0019 & $70 \%$ & 42.2 & 2.1 & 60.6 & 3.0 \\
\hline
\end{tabular}

composite there would be a better chance of observing P-glass particles wire drawing. The filament was dried for 4 hours at $80^{\circ} \mathrm{C}$ before printing. As was the case when evaluating the ABS:SEBS-g-MA system, in order to identify if printing temperature played a factor in the wire drawing of the Pglass particles and overall mechanical properties, additional printing temperatures were experimented with (in this case, four). Paired data pools (sets of two for composites and three for baseline specimens) were printed at the different temperatures as seen in Table 9 along with the corresponding mechanical test results. The mechanical testing was carried out following the same procedure explained earlier.

Figure 19 compares the UTS results of the dried versus undried filament for the pure PLA baseline and PLA 10\% Pglass system; in this graph it can be appreciated that the UTS slightly, though not significantly, increased, for the dried PLA baseline from $55.1 \pm 2.6$ to $57.6 \pm 1.5 \mathrm{MPa}$. In the case of the PLA/P-glass $10 \%$ system there was a significant increase in the UTS values when comparing it to the undried filament of the same load. The undried P-glass loaded filament data pool possessed an average UTS value of $48.4 \pm 2.8 \mathrm{MPa}$ when printed at $240^{\circ} \mathrm{C}$ while the dried filament printed at the same temperature reported a UTS value of $58.0 \pm 1.7 \mathrm{MPa}$, an increase of almost $20 \%$. The tensile strain at break for the PLA/P-glass $10 \%$ system was reduced from $4.4 \%$ for the undried filament printed at $240^{\circ} \mathrm{C}$ to $3.3 \%$ for the dried filament printed at the same temperature. The tensile strain at break for the dried filament surpassed the undried filament when printed at $260^{\circ} \mathrm{C}$ with a value of $4.7 \% \pm 0.6 \%$. Though the $\%$ EL at break was slightly reduced for some of the print temperature increments, it can be said that the drying of the filament improved the mechanical properties of PLA and the
PLA composites. Specifically, for the test specimens of PLA loaded with $10 \%$ by weight P-glass printed at $240^{\circ} \mathrm{C}$ where the UTS improved from $48.4 \pm 2.1 \mathrm{MPa}$ for the undried filament to $58.0 \pm 1.7 \mathrm{MPa}$ and still conserved similar strain elongation at break values from $4.4 \%$ (undried filament) to $4.7 \%$ (dried filament). Drying the filament gave the opportunity to be able to print at higher temperatures and still maintain the correct viscosity needed for a good quality ME3DP print. We were not able to print temperatures of $260^{\circ} \mathrm{C}$ without implementation of a filament drying cycle.

After performing mechanical testing of the new set of PLA/P-glass $10 \%$ system, fracture surfaces of the test coupons were analyzed via SEM in order to determine if the drying cycle had an effect on the wire drawing process. Analysis of SEM micrographs revealed that specimens printed at temperatures 220 and $230^{\circ} \mathrm{C}$ had similar fracture surface characteristics as the undried filament, some agglomeration, no in situ wire drawn particles, P-glass particle pullouts, and signs of well attached P-glass particles within the polymer matrix as it can be seen of Figure 20(a). Scanning electron microanalysis of the fracture surfaces of specimens from the $240^{\circ} \mathrm{C}$ and $260^{\circ} \mathrm{C}$ sample pool sets revealed many in situ wire drawn particles throughout the polymer matrix (Figure 20(b)). The drawn P-glass particles most likely played a role in the final mechanical properties of the specimens printed at $260^{\circ} \mathrm{C}$ as this sample pool exhibited the highest UTS values. The elongated P-glass particles seem to be longer than those found in the ABS:SEBS-g-MA polymer blend; however we were unable to approximate a length because they were still embedded within the polymer matrix. The shape of the in situ wire drawn particles of the PLA composite appears to be more cylindrical than the ones observed 
TABLE 8: Melt flow rate values for the materials tested in this study.

\begin{tabular}{lccc}
\hline Material & Melt flow rate $(\mathrm{g} / 10 \mathrm{~min})$ & Test load $(\mathrm{kg})$ & Temperature \\
\hline ABS SEBS-g-MA & $\mathbf{3 3 . 7 2}$ & $\mathbf{3 . 8}$ & $\mathbf{2 3 0}$ \\
P-glass 5\%, ABS SEBS-g-MA & 32.38 & 3.8 & 230 \\
P-glass 10\%, ABS SEBS-g-MA & 30.41 & 3.8 & 230 \\
P-glass 20\%, ABS SEBS-g-MA & 29.48 & 3.8 & 230 \\
PLA & $\mathbf{1 6 . 9 8}$ & 2.16 & $\mathbf{2 1 0}$ \\
PLA/P-glass 2.5\% & 34.36 & 2.16 & 210 \\
PLA/P-glass 5\% & 74.8 & 2.16 & 210 \\
PLA/P-glass 10\% & 85.56 & 2.16 & 210 \\
PLA/P-glass 15\% & 60.52 & & 210 \\
\hline
\end{tabular}
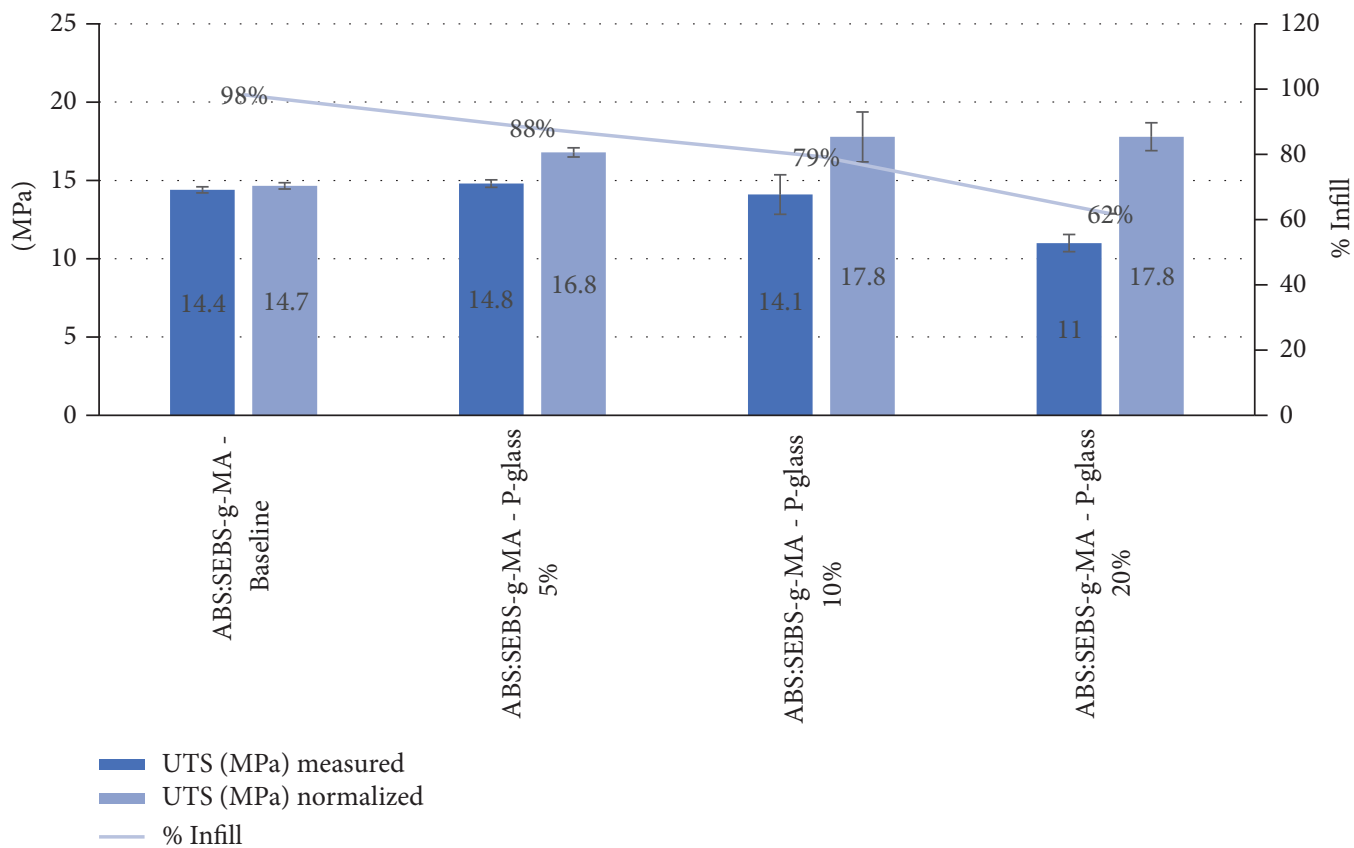

FIGURE 17: Normalization of UTS values for ABS:SEBS-g-MA system.

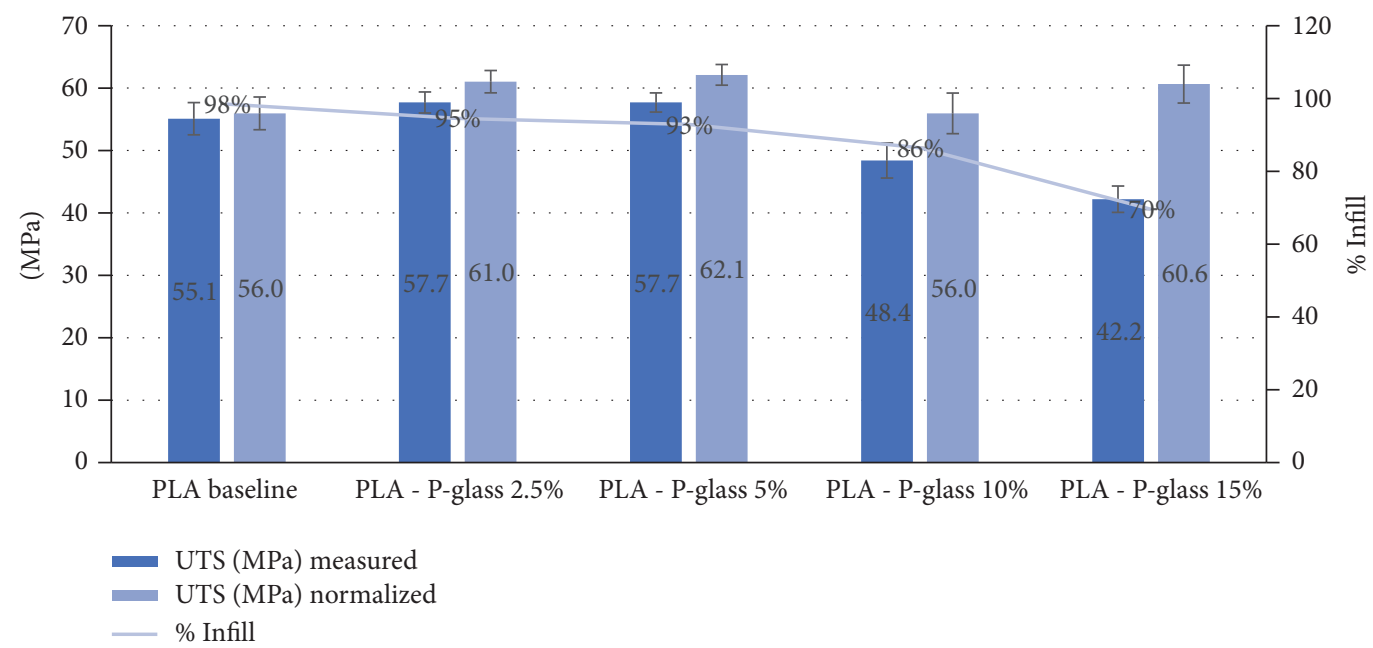

FIGURE 18: Normalization of UTS values for PLA system evaluated in this study. 
TABLE 9: Mechanical testing data for the PLA/P-glass 10\% system where the filament was dried before printing at different temperatures.

\begin{tabular}{|c|c|c|c|c|c|}
\hline Material & Ultimate tensile stress (MPa) & ST. DEV & Tensile strain at break (\%) & ST. DEV & Sample size $(n)$ \\
\hline PLA/P-glass 10\% @220 C & 57.1 & 2.9 & 3.2 & 1.6 & 3 \\
\hline PLA/P-glass 10\%@230 C & 56.8 & 0.7 & 2.9 & 0.2 & 3 \\
\hline PLA/P-glass 10\% @240 C & 58.0 & 1.7 & 3.3 & 0.4 & 3 \\
\hline PLA/P-glass 10\%@260 C & 57.5 & 0.9 & 4.7 & 0.6 & 3 \\
\hline PLA baseline@220ㄷ & 56.4 & 2.2 & 5.3 & 1.5 & 3 \\
\hline PLA baseline@230C & 56.2 & 2.2 & 3.0 & 0.6 & 3 \\
\hline PLA baseline @ 240 C & 57.6 & 1.5 & 4 & 1.1 & 3 \\
\hline PLA baseline@260 C & 59.5 & 2.6 & 4.4 & 0.9 & 3 \\
\hline
\end{tabular}

TABLE 10: Normalization of UTS values for dried PLA printed at $240^{\circ} \mathrm{C}$.

\begin{tabular}{|c|c|c|c|c|c|c|c|c|}
\hline Material & $\begin{array}{c}\text { Theoretical } \\
\text { density } \\
\left(\mathrm{g} / \mathrm{cm}^{3}\right)\end{array}$ & $\begin{array}{c}\text { Measured } \\
\text { density } \\
\left(\mathrm{g} / \mathrm{cm}^{3}\right)\end{array}$ & ST DEV & $\%$ infill & $\begin{array}{c}\text { UTS }(\mathrm{MPa}) \\
\text { measured }\end{array}$ & ST DEV & $\begin{array}{l}\text { UTS (MPa) } \\
\text { normalized }\end{array}$ & ST DEV \\
\hline PLA, dried & 1.3 & 1.2 & 0.0019 & $100 \%$ & 56.4 & 2.2 & 56.4 & 2.2 \\
\hline $\begin{array}{l}\text { PLA, P-glass } \\
10 \% \text {, dried }\end{array}$ & 1.5 & 1.3 & 0.0023 & $86 \%$ & 58 & 1.7 & 67.7 & 2.0 \\
\hline
\end{tabular}

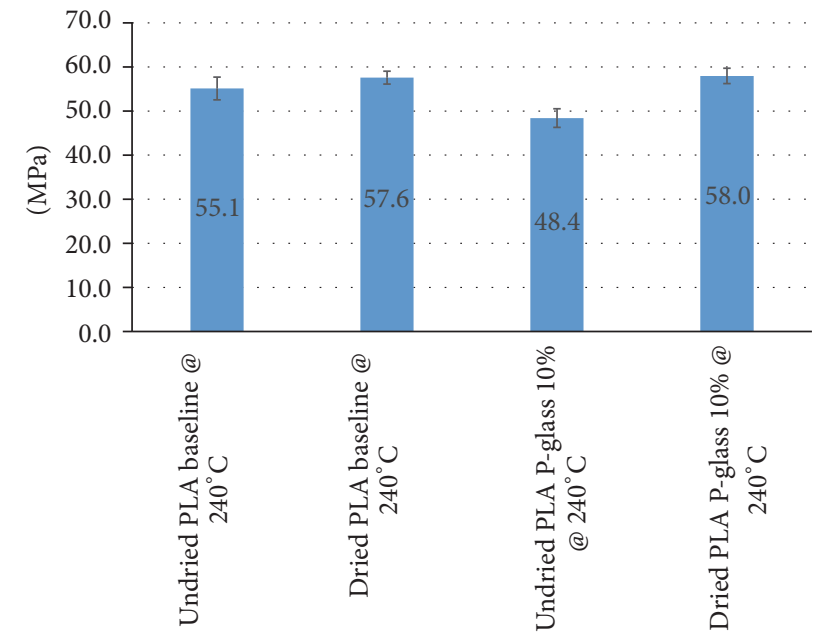

FIGURE 19: UTS values of undried versus dried PLA for the cases of neat resin and resin loaded with $10 \%$ by weight P-glass.

in the ABS:SEBS-g-MA composite where they exhibited a rougher cylindrical shape (Figure $4(\mathrm{a})$ ). This could be due to the differences in the rheology of the material systems; the viscosity found in the dried PLA composite represented higher shear forces in the P-glass particles and created sharper microrods of phosphate glass within the polymer matrix.

Again, we performed a normalization process of the UTS results for the dried versus undried PLA following the same experimental process explained above and the results are displayed in Table 10 and Figure 21. The trend of a decreased $\%$ infill with the increase in P-glass loading was maintained after drying the filament. As was the case with the undried filament, drying the filament resulted in $86 \%$ infill when loaded with $10 \%$ by weight P-glass meaning that the increase in UTS is attributed the drying process. Although the UTS is greater for the dried filament by $20 \%$ it leads to the conclusion that the different morphology of the P-glass present in this system had a profound effect on the mechanical properties as it was initially theorized.

\section{Conclusions}

We have demonstrated the creation of $3 \mathrm{D}$ printable thermoplastic composites loaded with low melting temperature phosphate glass. Combining this low melting temperature filler material with $3 \mathrm{D}$ printable thermoplastics, in this case PLA and a rubberized blend (50:50 by weight ratio of ABS and SEBS-g-MA) in some cases, led to wire drawing of the particles. When wire drawing was successful, there was a reduction in particle agglomeration. The ability to draw low melting temperature phosphate glass depends on many factors including polymer viscosity, particle filler size, and, particularly in the case of PLA, print temperature.

Initial results involving PLA revealed that the addition of P-glass at a $5 \%$ by weight loading increased the UTS by $4.5 \%$; however no wire drawing was observed. The drying of extruded PLA filament had a profound effect on the melt flow rate and later proved to be a key enabler for the achievement of wire drawing within PLA. Drying the PLA also enabled printing at higher temperatures, while maintaining a viscosity great enough to initiate wire drawing.

Normalization of tensile test data was paramount in understanding the result of the addition of P-glass on the mechanical strength of the material systems explored here. The process of 3D printing imparts voids in between the print rasters which effectively diminishes the cross-sectional area of a tensile specimen and, thus, the UTS values. Specific gravity measurements allowed for the development of normalization factors for each of the material systems to give an idea of the bulk material properties.

The work presented here demonstrates the $3 \mathrm{D}$ printing of a hybrid material system where the matrix and filler material possessed similar thermal properties. The similarity 


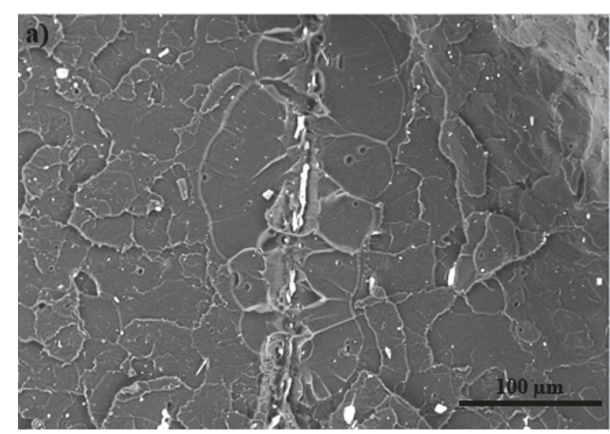

(a)

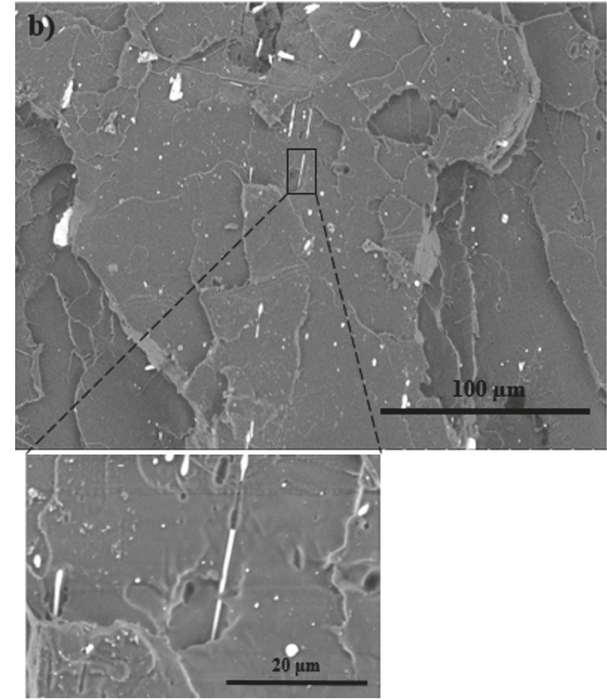

(b)

FIgURE 20: SEM micrograph of the fracture surface of PLA loaded with P-glass at $10 \%$ by weight printed at (a) $220^{\circ} \mathrm{C}$ and (b) $260^{\circ} \mathrm{C}$.

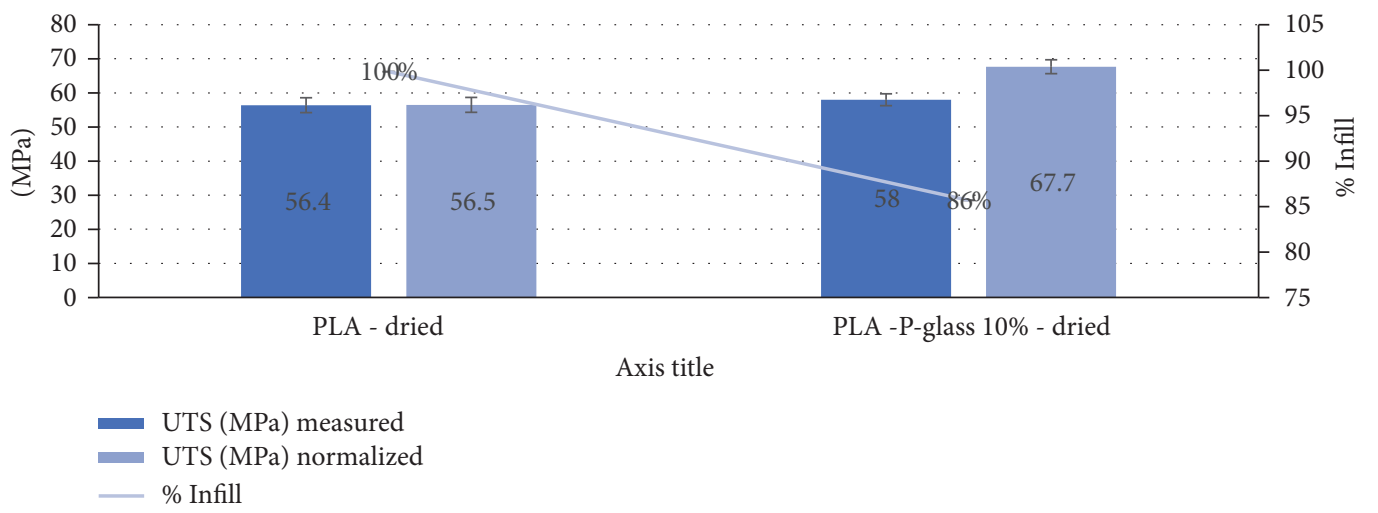

FIGURE 21: Normalization of UTS values for dried versus undried filament for the PLA system.

in properties allow, in some cases, the drawing of phosphate glass filler material into a wire-like morphology. The 3D printing process played more of a role in the wire drawing process than the filament fabrication process. The potential to create hybrid material-based 3D-printed structures from this and similar material systems will expand the frontiers of FDM-type 3D printing.

\section{Conflicts of Interest}

The authors declare no conflicts of interest in relation to the publication of this paper.

\section{Acknowledgments}

The work presented here was performed in the W.M. Keck Center for 3D Innovation (Keck Center) and the Department of Metallurgical, Materials and Biomedical Engineering (MMBME) at The University of Texas at El Paso (UTEP). The authors are grateful for the internal support from the Keck Center and use of the scanning electron microscopy complex in the MMBME department. Funding for this work was provided by the AFOSR through the Young Investigator Program (YIP) under Grant no. FA9550-14-1-0260 and the Defense University Instrumentation Program (DURIP) under Grant no. FA9550-15-1-0312.

\section{References}

[1] B. H. Stuart, Polymer Analysis, John Wiley Sons, 2008.

[2] A. A. Collyer, Rubber Toughened Engineering Plastics, Springer Science Business Media, 2012.

[3] J. Z. Liang and R. K. Y. Li, "Rubber toughening in polypropylene: a review," Journal of Applied Polymer Science, vol. 77, no. 2, pp. 409-417, 2000.

[4] J. G. Siqueiros, K. Schnittker, and D. A. Roberson, "ABSmaleated SEBS blend as a 3D printable material," Virtual and Physical Prototyping, vol. 11, no. 2, pp. 123-131, 2016. 
[5] Y. Xu, D. D. L. Chung, and C. Mroz, "Thermally conducting aluminum nitride polymer-matrix composites," Composites Part A: Applied Science and Manufacturing, vol. 32, no. 12, pp. 1749-1757, 2001.

[6] P. R. Hornsby, "Fire retardant fillers for polymers," International Materials Reviews, vol. 46, no. 4, pp. 199-210, 2001.

[7] G. Mittal, V. Dhand, K. Y. Rhee, S.-J. Park, and W. R. Lee, "A review on carbon nanotubes and graphene as fillers in reinforced polymer nanocomposites," Journal of Industrial and Engineering Chemistry, vol. 21, pp. 11-25, 2015.

[8] G. Koronis, A. Silva, and M. Fontul, "Green composites: a review of adequate materials for automotive applications," Composites Part B: Engineering, vol. 44, no. 1, pp. 120-127, 2013.

[9] S. Kumar and J.-P. Kruth, "Composites by rapid prototyping technology," Materials and Design, vol. 31, no. 2, pp. 850-856, 2010.

[10] M. L. Shofner, K. Lozano, F. J. Rodríguez-Macías, and E. V. Barrera, "Nanofiber-reinforced polymers prepared by fused deposition modeling," Journal of Applied Polymer Science, vol. 89, no. 11, pp. 3081-3090, 2003.

[11] S. J. Leigh, R. J. Bradley, C. P. Purssell, D. R. Billson, and D. A. Hutchins, "A Simple, Low-Cost Conductive Composite Material for 3D Printing of Electronic Sensors," PLoS ONE, vol. 7, no. 11, Article ID e49365, 2012.

[12] O. Ivanova, C. Williams, and T. Campbell, "Additive manufacturing (AM) and nanotechnology: promises and challenges," Rapid Prototyping Journal, vol. 19, no. 5, pp. 353-364, 2013.

[13] N. M. A. Isa, M. I. Ibrahim, N. Sa'ude, and M. Ibrahim, "Characterisation of copper filled in ABS material for freeform fabrication," ARPN Journal of Engineering and Applied Sciences, vol. 11, no. 9, pp. 6531-6535, 2016.

[14] S. Masood and W. Song, "Development of new metal/polymer materials for rapid tooling using fused deposition modelling," Materials \& Design, vol. 25, no. 7, pp. 587-594, 2004.

[15] M. Nikzad, S. H. Masood, and I. Sbarski, "Thermo-mechanical properties of a highly filled polymeric composites for Fused Deposition Modeling," Materials and Design, vol. 32, no. 6, pp. 3448-3456, 2011.

[16] G. Wu, N. A. Langrana, R. Sadanji, and S. Danforth, "Solid freeform fabrication of metal components using fused deposition of metals," Materials and Design, vol. 23, no. 1, pp. 97-105, 2002.

[17] L. J. Love, V. Kunc, O. Rios et al., "The importance of carbon fiber to polymer additive manufacturing," Journal of Materials Research, vol. 29, no. 17, pp. 1893-1898, 2014.

[18] H. L. Tekinalp, V. Kunc, G. M. Velez-Garcia et al., "Highly oriented carbon fiber-polymer composites via additive manufacturing," Composites Science and Technology, vol. 105, pp. 144150, 2014.

[19] S. Hwang, E. Reyes, K.-S. Moon, R. Rumpf, and N. Kim, "Thermo-mechanical characterization of metal/polymer composite filaments and printing parameter study for fused deposition modeling in the 3D printing process," Journal of Electronic Materials, vol. 44, no. 3, pp. 771-777, 2014.

[20] D. Roberson, C. M. Shemelya, E. MacDonald, and R. Wicker, "Expanding the applicability of FDM-type technologies through materials development," Rapid Prototyping Journal, vol. 21, no. 2, pp. 137-143, 2015.

[21] C. M. Shemelya, A. Rivera, A. T. Perez et al., "Mechanical, electromagnetic, and X-ray shielding characterization of a 3D printable tungsten-polycarbonate polymer matrix composite for space-based applications," Journal of Electronic Materials, vol. 44, no. 8, pp. 2598-2607, 2015.

[22] A. R. Torrado, C. M. Shemelya, J. D. English, Y. Lin, R. B. Wicker, and D. A. Roberson, "Characterizing the effect of additives to ABS on the mechanical property anisotropy of specimens fabricated by material extrusion 3D printing," Additive Manufacturing, vol. 6, pp. 16-29, 2015.

[23] H. Ku, H. Wang, N. Pattarachaiyakoop, and M. Trada, "A review on the tensile properties of natural fiber reinforced polymer composites," Composites Part B: Engineering, vol. 42, no. 4, pp. 856-873, 2011.

[24] M. Gupta, Y. Lin, T. Deans et al., "Biaxially oriented poly(propylene-g-maleic anhydride)/phosphate glass composite films for high gas barrier applications," Polymer, vol. 50, no. 2, pp. 598-604, 2009.

[25] A. M. Papadopoulos, "State of the art in thermal insulation materials and aims for future developments," Energy and Buildings, vol. 37, no. 1, pp. 77-86, 2005.

[26] X. Xu, F. L. Harding, and M. A. Albers, Glass compositions for high thermal insulation efficiency glass fibers, US5932499 A, 1999. http://www.google.com/patents/US5932499.

[27] C. J. Kief, J. Aarestad, E. MacDonald et al., "Printing multifunctionality: additive manufacturing for cubesats," in Proceedings of the AIAA SPACE 2014 Conference and Exposition, August 2014.

[28] E. MacDonald, R. Salas, D. Espalin et al., "3D printing for the rapid prototyping of structural electronics," IEEE Access, vol. 2, pp. 234-242, 2014.

[29] Standard Test Method for Tensile Properties of Plastics, ASTM International, 2014.

[30] Standard Test Method for Melt Flow Rates of Thermoplastics by Extrusion Plastometer, ASTM International, 2013.

[31] B. N. Turner, R. Strong, and S. A. Gold, "A review of melt extrusion additive manufacturing processes: I. Process design and modeling," Rapid Prototyping Journal, vol. 20, no. 3, Article ID 17111231, pp. 192-204, 2014.

[32] Standard Test Method for Density and Specific Gravity of Plastics by Displacement, ASTM International, 2013.

[33] A. A. Natureworks, R. Kean, T. Schechinger, S. Birrell, and J. Euken, "Final Technical Report," Tech. Rep. DOE/ID/14216-1, 2007. 

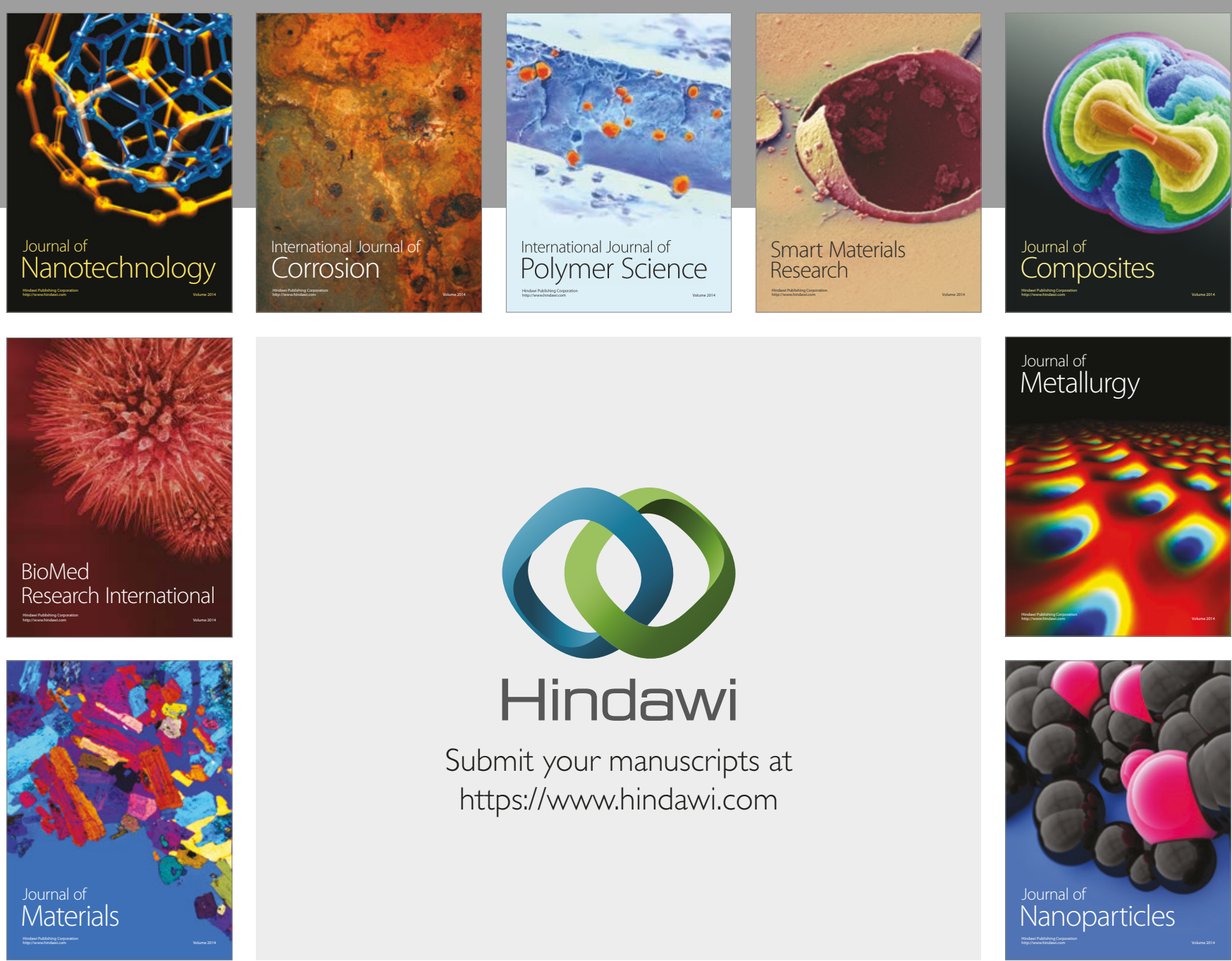

\section{Hindawi}

Submit your manuscripts at

https://www.hindawi.com
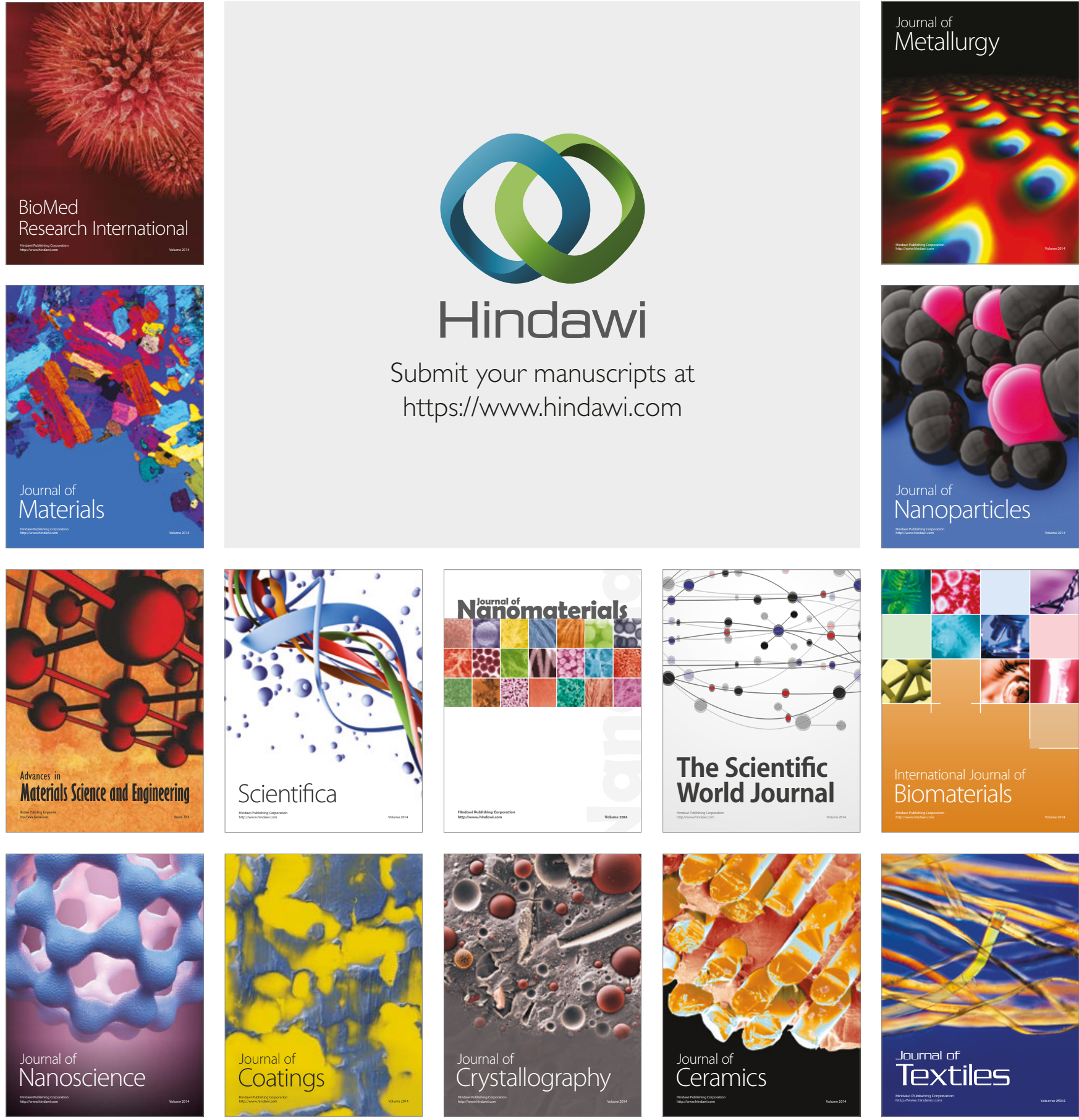

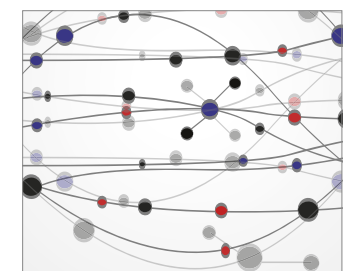

The Scientific World Journal
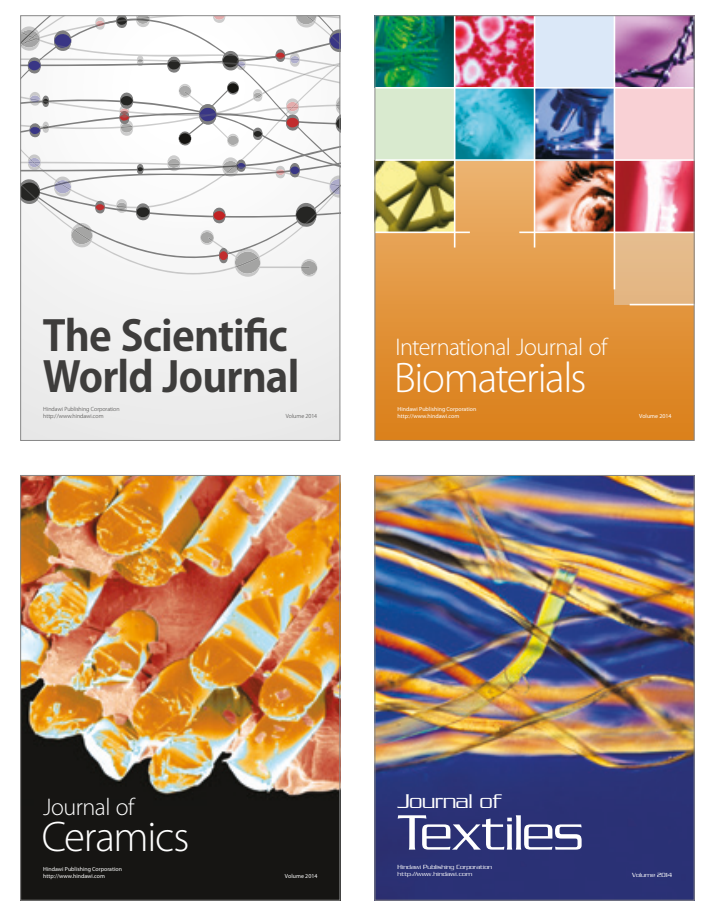